\title{
Preparation and Characterization of Binary and Ternary Blends with Poly(Lactic Acid), Polystyrene, and Acrylonitrile-Butadiene-Styrene
}

\author{
Kotiba Hamad*, Mosab Kaseem, Fawaz Deri \\ Laboratory of Materials Rheology (LMR), Department of Chemistry, Faculty of Science, University of Damascus, Damascus, Syria. \\ Email: *kotibahamad@yahoo.com
}

Received October $12^{\text {th }}, 2011$; revised March $16^{\text {th }}, 2012$; accepted May $20^{\text {th }}, 2012$

\begin{abstract}
Binary and ternary blends of poly(lactic acid) (PLA), polystyrene (PS) and acrylonitrile-butadiene-styrene (ABS) were prepared using a one-step extrusion process. Rheological and mechanical properties of the prepared blends were determined. Rheological properties were studied using a capillary rheometer, shear rate, shear stress, non-Newtonian index, shear viscosity and flow activation energy were determined. Mechanical properties were studied in term of tensile properties, stress at break, strain at break, and Young's modulus was determined. The effect of the composition on the rheological and mechanical properties was investigated. The results show that the ternary blend exhibits shear-thinning behavior over the range of the studied shear rates where the true shear viscosity of the blend decreases with increasing true shear rate, also it was found that the true viscosity of the blend decreases with increasing ABS content. The mechanical results showed that, in the most cases, the stress at break and the Young's modulus improved by the addition of ABS.
\end{abstract}

Keywords: PLA; Ternary Blends; Rheology; Mechanical Properties

\section{Introduction}

Increasing concerns over the environmental impact and sustainability of conventional polymer materials have motivated academia and industry to devote considerable efforts to the development of polymers from renewable resources. Among a few commercially available biobased or partially bio-based thermoplastic polymers, poly (lactic acid) (PLA) has undergone the most investigation. PLA is one of the most important biodegradable polyesters which could be processed using the traditional processing techniques (extrusion, injection...) and it has better thermal processability compared to other biopolymers such as poly(hydroxyl alkanoates) (PHAs), poly (ethyele glycol) (PEG), polycaprolactone (PCL), etc [1]. Due to its initial production costs, the starting applications of PLA have been focused on high value products such as medical devices [2]. Advances in the polymerization technology have significantly reduced the production cost and have contributed to make PLA economically competitive with petroleum-based polymers. PLA's potential for food packaging is very high due to its transparency, mechanical properties and acceptable moisture processability for dry food stuff [1]. Nevertheless, there

${ }^{*}$ Corresponding author. are some drawbacks, such as its high brittleness and poor crystallization behavior that limit its current use in food packaging [3]. In order to overcome these limitations, the copolymerization of lactic acid with other monomers has been a widely used approach, but without any success for commercial application. A less expensive and more practical strategy to overcome these drawbacks is the blending of PLA with other polymers. Hence, several synthetic polymers and copolymers such as, polyethylene (PE) [4-7], polypropylene (PP) [8-11], polystyrene (PS) [12$16]$, poly (ethylene terephtalate) (PET) $[17,18]$, polycarbonate (PC) [19], polyamide (PA) [20], and acrylonitrile-butadiene-styrene (ABS) [21] or biodegradable polymers such as polycaprolactone [22-27], poly(butylene succinate) (PBS) [28-32], poly(butylenes adipateco-terephtalate) (PBAT) [33-39], thermoplastic starch (TPS) [40-45] and poly(butylene succinate adipate) (PBSA) $[46,47]$ have been used.

Preparation and characterization of PLA/PS polymer blends were reported in many works [12-16], it was found in these works that the thermal stability of the blend is better than that of pure PLA. Also it was found that the blend has good processability. Nevertheless, drawbacks were noted in this blend (PLA/PS), such as lower mechanical properties (tensile strength and modu- 
lus) comparing with those of pure PLA. From another side ABS was used for improving the impact strength of PLA, Li and Shimizu [21] used ABS for toughening PLA. Blends of PLA and ABS in different ratios were prepared and as the in-situ compatibilizer for PLA/ABS blends to improve the compatibility between PLA and ABS, the reactive styrene-acrylonitrile-glycidyl methacrylate copolymer (SAN-GMA) by incorporating with ethyltriphenyl phosphonium bromide (ETPB) as the catalyst was used. The mechanical results showed that impact strength of the compatibilized blend is higher than that of uncompatibilized and pure PLA, but the modulus of the compatibilized blend was less than that of pure PLA. In this work ternary blends of PLA, PS, ABS were prepared in efforts to obtain new materials with improved mechanical properties, such works are very important in the development of composites and blends from biodegradable polyesters.

\section{Experimental}

\subsection{Materials}

Poly(lactic acid) (PLA) (ESUN ${ }^{\mathrm{TM}}$ A-1001) [density = $1.25 \mathrm{~g} / \mathrm{cm}^{3}\left(21.5^{\circ} \mathrm{C}\right), M F I=12.5 \mathrm{~g} / 10 \mathrm{~min}\left(190^{\circ} \mathrm{C} / 2.18\right.$ $\mathrm{kg}$ )] was supplied by Bright China Industrial Company. Ltd (Shenzhen, China), the selected grade is an extrusion material; it was dried at $70^{\circ} \mathrm{C}$ for 6 hours before using. Polystyrene (PS) $\left(\mathrm{SABIC}^{\circledR} 125 \mathrm{PS}\right.$ ) [density $=1.05 \mathrm{~g} / \mathrm{cm}^{3}$, $\left.M F I=7 \mathrm{~g} / 10 \mathrm{~min}\left(200^{\circ} \mathrm{C} / 5 \mathrm{~kg}\right)\right]$ was supplied by Sabic (KSA). Acrylonitrile-Butadiene-Styrene (ABS) (Kumho ABS 750SW) was supplied by Korea Kumho Petrochemical Co., Ltd. (Korea), [density $=1.04 \mathrm{~g} / \mathrm{cm}^{3}, M F R$ $\left.=50 \mathrm{~g} / 10 \mathrm{~min}\left(200{ }^{\circ} \mathrm{C} / 21.6 \mathrm{~kg}\right)\right]$.

\subsection{Blends Preparation}

Binary and ternary blends of PLA, PS, and ABS in different ratios were prepared using a laboratory scale single screw extruder (SSE) $(D=20 \mathrm{~mm}, L / D=25)$ [SHAM EXTRUDER 25D Performance: Kreem Industrial Establishment, Damascus, Syria]. The screw has a fluted type mixing section located before the metering zone [48], in this type of mixers the material is forced to pass at a high shear stress. This brings in some level of dispersing action besides reorienting the interfacial area, and increasing the imposed total strain. The screw speed was set at $40 \mathrm{rpm}$ in the blends preparation, and the extruder temperature profile along the barrel was $130^{\circ} \mathrm{C}$, $140^{\circ} \mathrm{C}, 150^{\circ} \mathrm{C}, 160^{\circ} \mathrm{C}$ (from feed zone to die). The blends were extruded through a multi holes die $(3 \mathrm{~mm})$, the extrudates were then fed into a granulator, which converted them into granules. The obtained granules were dried at $70^{\circ} \mathrm{C}$ for $6 \mathrm{~h}$ before studying. The compositions of the blends are shown in Table 1.

\subsection{Tensile Samples Preparation}

The prepared granules were injection molded at $190^{\circ} \mathrm{C}$ $210^{\circ} \mathrm{C}$ using NEGRI BOSSI (NB 25) injection machine (Lessona Corporation, Italy). The tensile samples were prepared according to the following injection conditions, cooling time in the mold was $15 \mathrm{sec}$, the mold temperature was room temperature with water-cooling $\left(25^{\circ} \mathrm{C}\right)$ and injection pressure was $9 \mathrm{MPa}$. The molded samples were dog bone-shaped samples with a thickness and width of $4 \mathrm{~mm}$ and $10 \mathrm{~mm}$ respectively. The gauge length of the sample was $80 \mathrm{~mm}$ (Figure 1). The obtained products were immediately packed in plastics bags and stored in a dark cool surrounding.

\subsection{Rheological Properties}

Rheological experiments were carried out using a capillary rheometer (Davenport 3/80), the rheological experiments were carried out at $165,175,185$ and $195^{\circ} \mathrm{C}$, and by using $L / R=8,15,25$ and 36 capillaries. Bagley's correction [49] was performed by using the data from the four capillary dies. The apparent shear rate $\left(\gamma_{a}\right)$ is given by:

$$
\gamma_{a}=\frac{4 Q}{\pi \cdot R^{3}}
$$

where $R$ is the capillary radius, and $Q$ is the volumetric flow rate. The true shear rate $\left(\gamma_{r}\right)$ is given by:

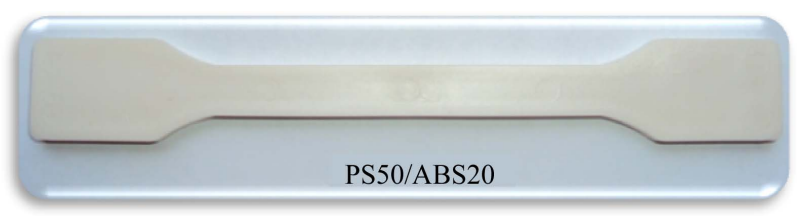

Figure 1. Injection molded sample of PS50/ABS20 blend.

Table 1. Compositions of the binary and ternary blends.

\begin{tabular}{cccccccccc}
\hline Sample & PS30/ABS0 & PS50/ABS0 & PS70/ABS0 & PS50/ABS5 & PS50/ABS10 & PS50/ABS15 & PS50/ABS20 & PS70/ABS20 & PS30/ABS20 \\
\hline PLA (wt $\%)$ & 70 & 50 & 30 & 50 & 50 & 50 & 50 & 30 & 70 \\
PS (wt $\%)$ & 30 & 50 & 70 & 50 & 50 & 50 & 50 & 70 & 30 \\
ABS ( ${ }^{*}$ phr) & 0 & 0 & 0 & 5 & 10 & 15 & 20 & 20 & 20 \\
\hline
\end{tabular}

" phr: part per hundred of PLA/PS blend. 


$$
\gamma_{r}=\left(\frac{3 n+1}{4 n}\right) \gamma_{a}
$$

where $n$ is the non-Newtonian index depending on temperature, the term $\left(\frac{3 n+1}{4 n}\right)$ was the Rabinowitsch correction factor. The apparent shear stress $\left(\tau_{a}\right)$ is given by:

$$
\tau_{a}=\frac{\Delta P}{2\left(\frac{L}{R}\right)}
$$

where $\Delta P$ is the pressure at the capillary entrance, and $L$ is the capillary length. The true shear stress $\left(\tau_{r}\right)$ is given by:

$$
\tau_{r}=\frac{\Delta P}{2\left(\frac{L}{R}+e\right)}
$$

where $e$ is the Bagley's correction factor. The true viscosity $\left(\eta_{r}\right)$ is given by:

$$
\eta_{r}=\frac{\tau_{r}}{\gamma_{r}}
$$

The values of flow activation energy at a constant shear rate $\left(E_{\gamma}\right)$ were determined using Arrhenius equation form:

$$
\eta_{r}=A \cdot e^{\frac{E_{\gamma}}{R T}}
$$

where $A$ is the consistency related to structure and formulation and $R$ is the gas constant $(8.314 \mathrm{~J} /(\mathrm{mol} \cdot \mathrm{K}))$.

\subsection{Mechanical Properties}

Tensile testing to study stress at break $\left(\mathrm{N} / \mathrm{mm}^{2}\right)$, strain at break (\%) and Young's modulus $\left(\mathrm{N} / \mathrm{mm}^{2}\right)$ were performed using Testometric M350-10KN (The Testometric Company Ltd., Rochdale, UK) at room temperature, all samples were strained at $50 \mathrm{~mm} / \mathrm{min}$. Samples were conditioned at room temperature for a period of $48 \mathrm{~h}$ prior to testing. Results from 6 - 8 specimens were averaged.

\section{Results and Discussion}

\subsection{Rheological Properties}

\subsubsection{Flow Curves}

Polymer rheology in the molten state is very important for determining the processing conditions of the materials. Figure 2 shows the relationship between apparent shear rate and apparent shear stress (flow curves) for the ternary blend at $165^{\circ} \mathrm{C}$.

It is clearly seen from Figure 2 that the relationship between shear stress and shear rate obeys the power law in the range of the studied shear rates.

$$
\tau=K \gamma^{n}
$$

where $K$ is the consistency index and $n$ is the non-Newtonian index, which can be calculated from the slope of the lines in Figure 2. The same relationship was obtained for both polymers and binary polymer blends. Figure 3 shows the effect of ABS content on the $n$ of the blend at $165^{\circ} \mathrm{C}$. It could be noted from Figure 3 that the values of $n$ were less than 1, implying that PLA/PS/ABS blend melts were pseudo plastic; similar to most polymer and binary polymer blends in the molten state. No attention has been given in the past to flow behavior of the ternary polymer blends. Also it could be noted from Figure 3 that the values of $n$ for the ternary blend (PLA/PS/ABS) is less than that of the binary blend (PLA/PS (50/50)). The value of $n$ describes the deviation from the Newtonian fluids about flow behavior, so it is also called the flow behavior index. A higher value of $n$ reveals less influence of shear rate on flow behavior. In other words, the changes in viscosity upon shear rate are not obvious, so it could be said that the flow behavior of ternary blend

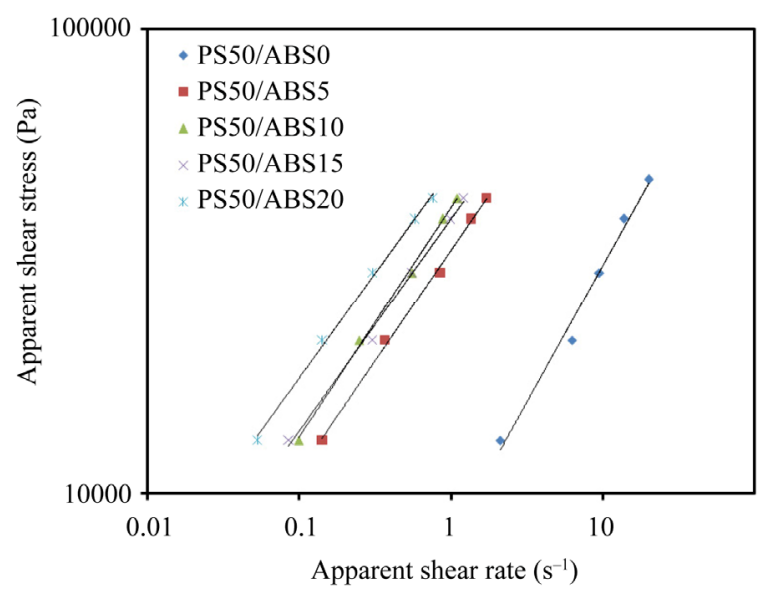

Figure 2. Flow curves of the blends at $165^{\circ} \mathrm{C}$.

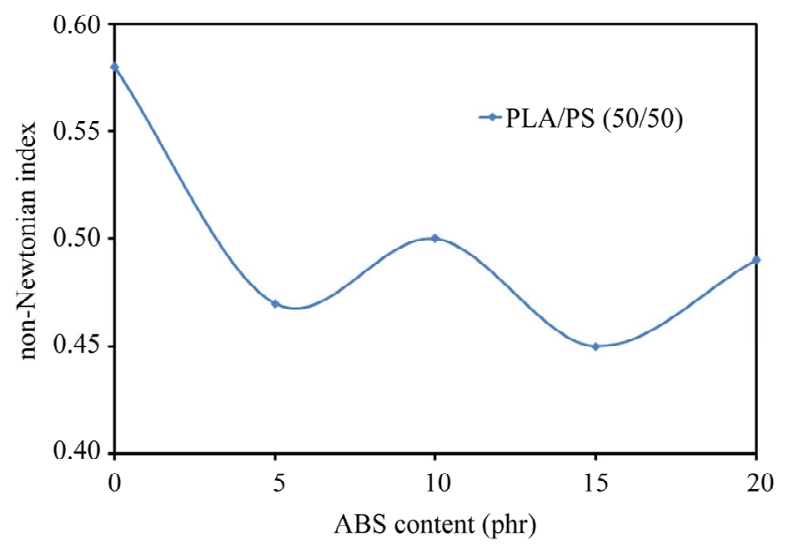

Figure 3. The effect of ABS content on the non-Newtonian index of the blends at $165^{\circ} \mathrm{C}$. 
melts is more sensitive to shear rate as compared with the binary blend (PLA/PS (50/50)).

\subsubsection{Viscosity Curves}

Figure 4 shows the relationship between true shear viscosity and true shear rate (viscosity curves) for the blends at $165^{\circ} \mathrm{C}$. It could be noted from Figure 4 that the true shear viscosity of the blends decreases with increasing true shear rate in the studied range of the shear rates, showing a typical property of shear-thinning, this behavior was attributed to the alignment or arrangement of chain segments of polymers in the direction of applied shear stress. The high shear viscosity at a low shear rate provide the integrity of the extrudate during extrusion, and the low shear viscosity at a high shear rate enables low injection pressure, high injection speed and less time of the injection cycle.

Figure 5 shows the plots of true viscosity versus blending ratio at $165^{\circ} \mathrm{C}$ and at shear rate $=10 \mathrm{~s}^{-1}$. It could be seen from Figure 5 that the true shear viscosity of the binary blend (PLA/PS) decreases with increasing PLA content in the blend and this behavior can be attributed to

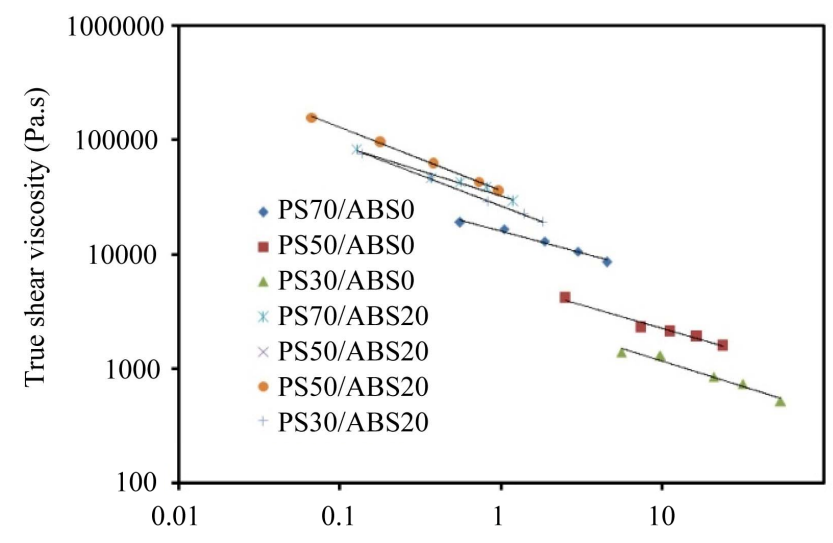

the low melt viscosity of PLA comparing with that of pure PS. Also it could be noted from Figure 5 that the viscosity of the binary blends is less than that of the ternary blends, where the addition of $5 \mathrm{phr}$ of ABS to PLA/PS (50/50) enhanced the true shear viscosity by a factor of 2.22 and by a factor 2.62 at $10 \mathrm{phr}$ ABS.

\subsubsection{Flow Activation Energy}

Figure 6 shows the relationship between true shear viscosity and $1 / T$ of the ternary blends at shear rate $=10 \mathrm{~s}^{-1}$, it could be noted from Fig. 6 that the true shear viscosity decreases with increasing temperature. With a rise of temperature the motion ability of polymer chains enhances, and the resistance between the melt layers decreases relevantly, leading to reduction of the melt viscosity.

The plots of true shear viscosity versus $1 / T$ shown in Figure 6 give a group of straight lines, which indicates that the relationship between the true viscosity and temperature follows Arrhenius equation (Equation (6)). Flow activation energy at a constant shear rate $\left(E_{\gamma}\right)$ could be calculated from the slopes of these lines.

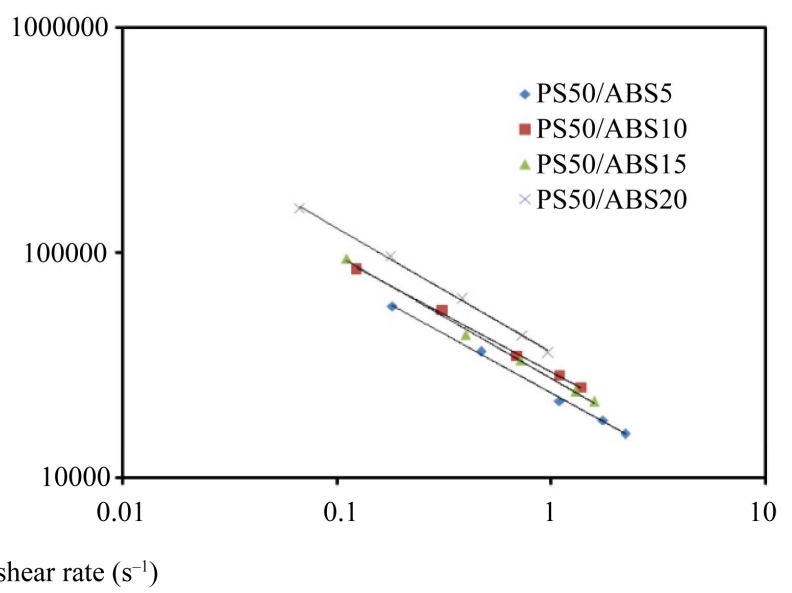

Figure 4. True shear viscosity versus true shear rate of the blends at $165^{\circ} \mathrm{C}$.
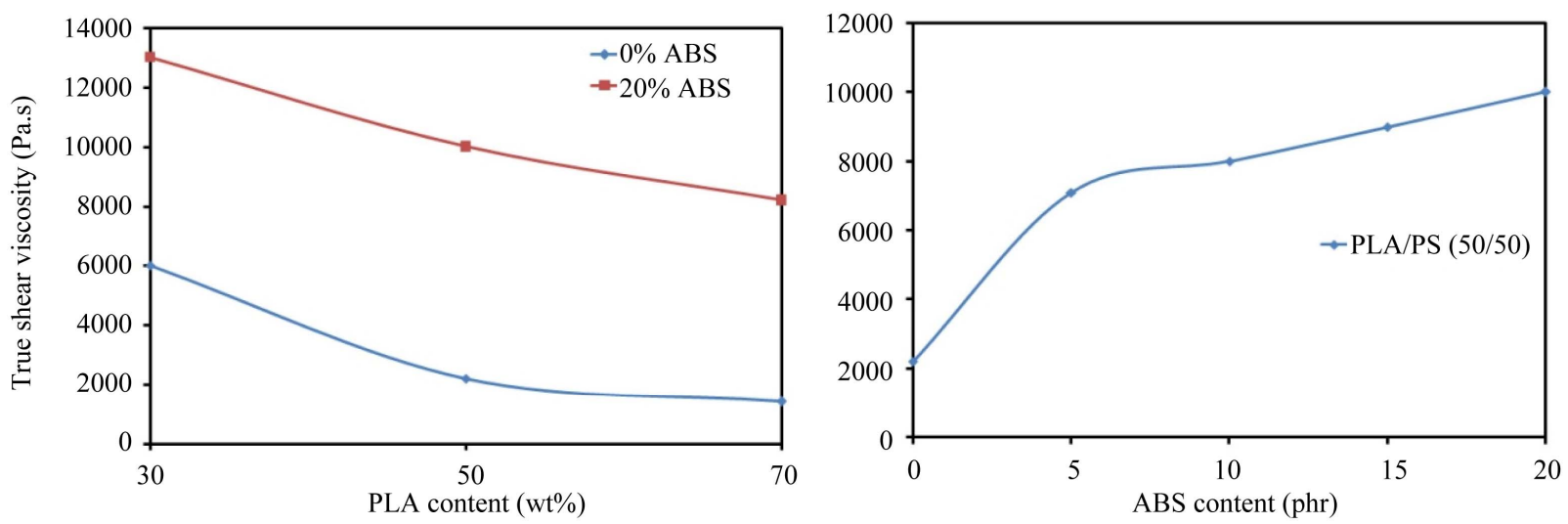

Figure 5. True shear viscosity of the blends at $165^{\circ} \mathrm{C}$ and $\gamma=10 \mathrm{~s}^{-1}$. 


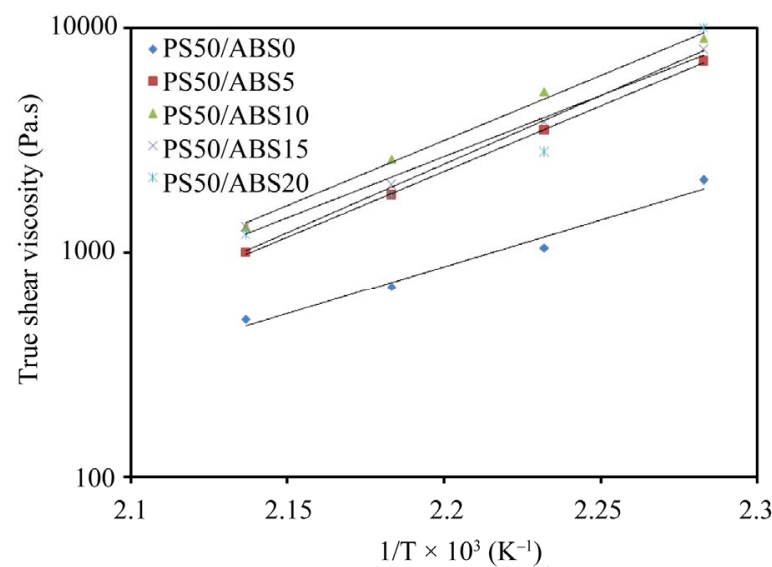

Figure 6. True viscosity versus $1 / T$ of the blends at $\gamma=10$ $\mathrm{s}^{-1}$.

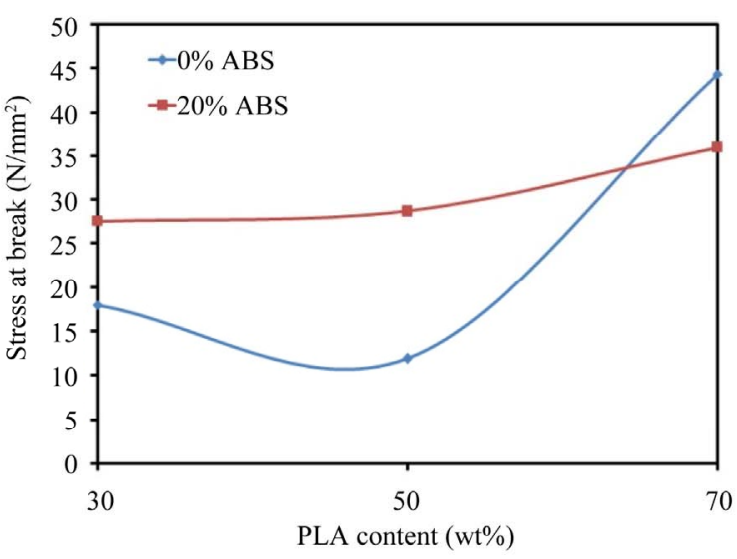

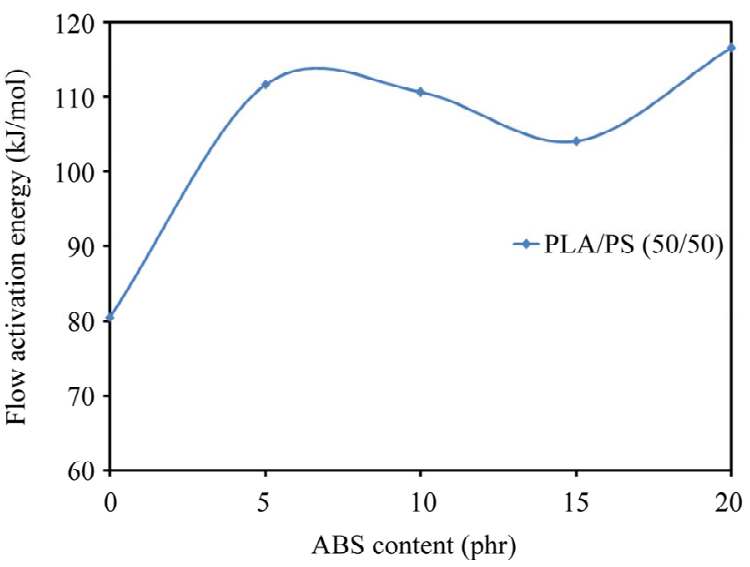

Figure 7. The effect of ABS content on the flow activation energy at a constant shear rate $\left(\gamma=10 \mathrm{~s}^{-1}\right)$.

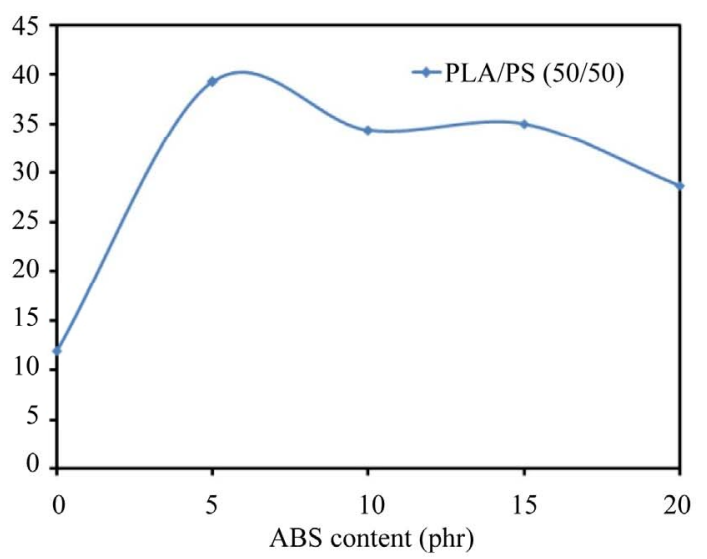

Figure 8. Stress at break of the blends.

$$
E_{\gamma}=R\left(\frac{\mathrm{d} \log \eta_{r}}{\mathrm{~d}(1 / T)}\right)_{\gamma}
$$

Figure 7 shows the effect of ABS content on the flow activation energy at a constant shear rate $\left(\gamma=10 \mathrm{~s}^{-1}\right)$.

It could be noted from Figure 7 that the flow activation energy of the binary blend (PLA/PS (50/50)) is less than that that of the ternary blends, so it could be said that adding ABS caused in increasing flow activation energy. It is well known that the value of flow activation energy reflects the temperature-sensitivity of viscosity, so the more $E_{\gamma}$ was the more sensitive the behavior of blends were to the temperature so it could be said that ternary blends are more sensitive to the temperature than the binary blend (PLA/PS (50/50)).

\subsection{Mechanical Properties}

Mechanical properties of the blends were determined in term of tensile properties, stress at break, strain at break, and Young's modulus were determined. Figure 8 shows the stress at break of the blends.

It could be noted from Figure 8 that the addition of ABS improves the stress at break of binary blend (PLA/ PS (50/50)), where adding 5 phr ABS to PLA/PS (50/50) enhanced the stress at break by a factor of 2.29 , also adding $20 \mathrm{phr}$ ABS to PLA/PS (30/70) and PLA/PS (50/ 50) enhanced the stress at break by factors 0.53 and 1.4 respectively.

Figure 9 shows the strain at break of the blends, it could be noted from Figure 9 that the strain at break of the ternary blends is more than that of the binary blend (PLA/PS (50/50)). Also it could be noted that the strain at break of PLA/PS (30/70) increases by a factor of 1.41 by the addition of $20 \mathrm{phr}$.

Figure 10 shows the Young's modulus of the blends, it could be noted from Figure 10 that the Young's modulus of the ternary blends is more than that of the binary blends. It could be noted from Figures $\mathbf{8}$ and $\mathbf{1 0}$ that the ternary blend (PS50/ABS5) has good mechanical properties 

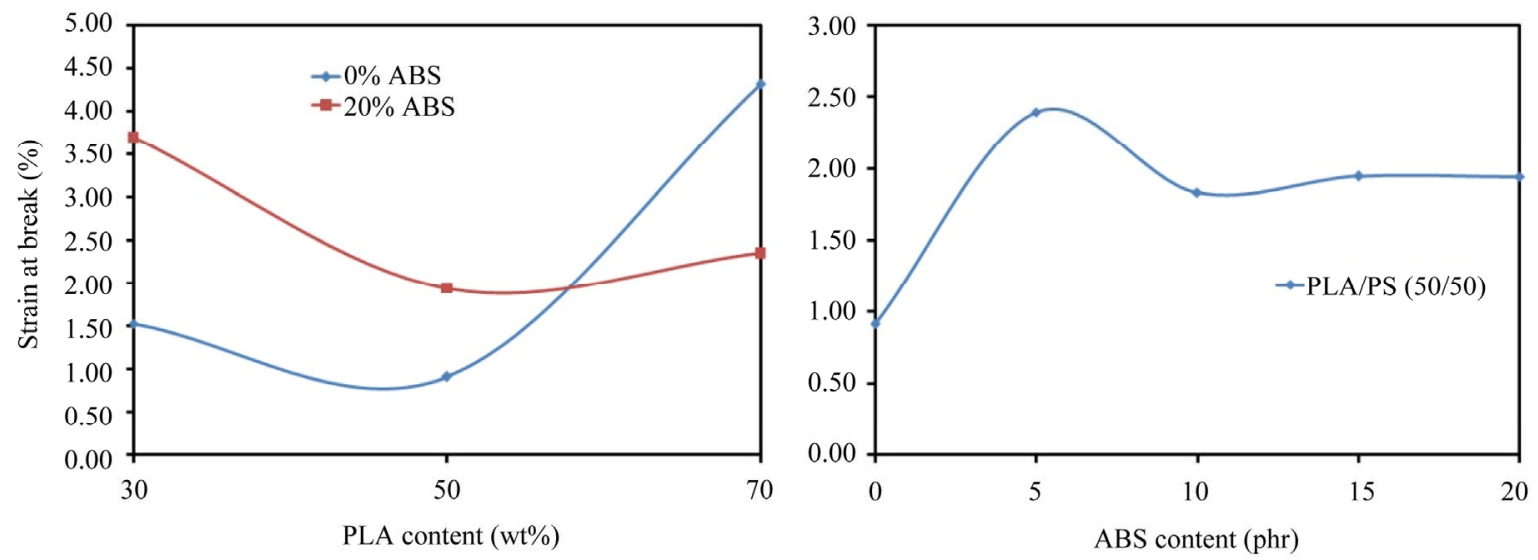

Figure 9. Strain at break of the blends.
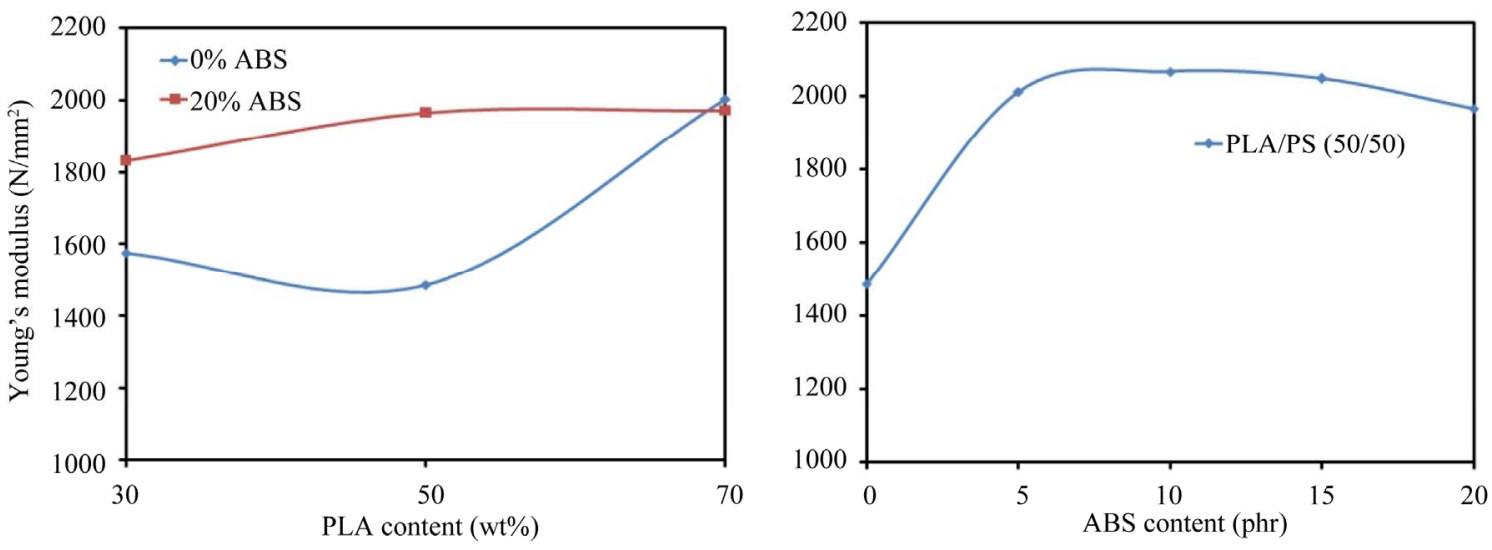

Figure 10. Young's modulus of the blends.

(stress at break and Young's modulus) which is similar to those of pure PLA (stress at break $=56 \mathrm{~N} / \mathrm{mm}^{2}$ and Young's modulus $=2220 \mathrm{~N} / \mathrm{mm}^{2}$ ).

\section{Conclusion}

In this work, rheological and mechanical properties of binary and ternary blends with poly(lactic acid), polystyrene, and acrylonitrile-butadiene-styrene were studied. The blends were prepared using a single screw extruder. Rheological results showed that the ternary blend (PLA/ $\mathrm{PS} / \mathrm{ABS}$ ) is pseudo plastic in nature; its viscosity decreases with increasing shear rate similar to most polymer and polymer blend melts. Also it was found that the true shear viscosity of the binary blend (PLA/PS) decreases with increasing PLA content which was attributed to PLA low viscosity, and the true shear viscosity of the ternary blend is more than that of the binary blend. The mechanical results showed that the stress at break and Young's modulus of the ternary blend are better than those of the binary blend. PS50/ABS5 blend showed good mechanical properties near to the mechanical properties of pure PLA.

\section{Acknowledgements}

The staff of Laboratory of materials rheology will not forgot Mr. Fahad Hamad.

\section{REFERENCES}

[1] R. Auras, B. Harte and S. Selke, "An Overview of Polylactides as Packaging Materials," Macromolecular Bioscience, Vol. 4, No. 9, 2004, pp. 835-864. doi:10.1002/mabi.200400043

[2] J. Lunt, "Larg-Scale Production, Properties and Commercial Applications of Poly Lactic Acid Polymers," Polymer Degradation and Stability, Vol. 59, No. 1-3, 1998, pp. 145-152. doi:10.1016/S0141-3910(97)00148-1

[3] M. Huneault and H. Li, "Morphology and Properties of Compatibilized Polylactide/Thermoplastic Starch Blends," Polymer, Vol. 48, No. 1, 2007, pp. 270-280. doi:10.1016/j.polymer.2006.11.023

[4] Y. F. Kim, et al., "Compatibilization of Immiscible Poly (L-Lactide) and Low Density Polyethylene Blends," Fibers and Polymers, Vol. 5, No. 4, 2004, pp. 270-274. doi:10.1007/BF02875524

[5] K. S. Anderson and M. A. Hillmyer, "The Influence of 
Block Copolymer Microstructure on the Toughness of Compatibilized Polylactide/Polyethylene Blends," Polymer, Vol. 45, No. 26, 2004, pp. 8809-8823. doi:10.1016/i.polymer.2004.10.047

[6] H. Balakrishnan, et al., "Mechanical, Thermal, and Morphological Properties of Polylactic Acid/Linear Low Density Polyethylene Blends," Elastic Plastic, Vol. 42, No. 3, 2010, pp. 223-239.

doi: $10.1177 / 0095244310362403$

[7] G. Singh, et al., "Mechanical Properties and Morphology of Polylactide, Linear Low-Density Polyethylene, and Their Blends," Journal of Applied Polymer Science, Vol. 118, 2010, pp. 496-502.

[8] A. Bourmaud and S. Pimbert, "Investigations on Mechanical Properties of Poly(Propylene) and Poly(Lactic Acid) Reinforced by Miscanthus Fibers," Composites Part A: Applied Science and Manufacturing, Vol. 39, No. 9, 2008, pp. 1444-1454. doi:10.1016/j.compositesa.2008.05.023

[9] N. Reddy, D. Nama and Y. Yang, "Polylactic Acid/ Polypropylene Polyblend Fibers for Better Resistance to Degradation," Polymer Degradation and Stability, Vol. 93, No. 1, 2008, pp. 233-241. doi:10.1016/j.polymdegradstab.2007.09.005

[10] W. T. Yoo, et al., "Effects of Compatibilizers on the Mechanical Properties and Interfacial Tension of Polypropylene and Poly(Lactic Acid) Blends," Macromolecular Research, Vol. 18, No. 6, 2010, pp. 583-588. doi:10.1007/s13233-010-0613-y

[11] K. Hamad, M. Kaseem and F. Deri, "Rheological and Mechanical Characterization of Poly(Lactic Acid)/Polypropylene Polymer Blends," Journal of Polymer Research, Vol. 18, No. 6, 2011, pp. 1799-1806. doi:10.1007/s10965-011-9586-6

[12] G. Biresaw and C. J. Carriere, "Interfacial Tension of Poly(Lactic Acid)/Polystyrene Blends," Journal of Polymer Science Part B: Polymer Physics, Vol. 40, No. 19, 2002, pp. 2248-2258. doi:10.1002/polb. 10290

[13] G. Biresaw and C. J. Carriere, "Compatibility and Mechanical Properties of Blends of Polystyrene with Biodegradable Polyesters," Composites Part A: Applied Science and Manufacturing, Vol. 35, No. 3, 2004, pp. 313-320. doi:10.1016/j.compositesa.2003.09.020

[14] A. Mohamed, et al., "Poly(Lactic Acid)/Polystyrene Bioblends Characterized by Thermogravimetric Analysis, Differential Scanning Calorimetry, and Photoacoustic Infrared Spectroscopy," Journal of Applied Polymer Science, Vol. 106, No. 3, 2007, pp. 1689-1696. doi:10.1002/app.26783

[15] K. Hamad, et al., "Rheological and Mechanical Properties of Poly(Lactic Acid)/Polystyrene Polymer Blend," Polymer Bulletin, Vol. 65, No. 5, 2010, pp. 509-519. doi:10.1007/s00289-010-0354-2

[16] K. Hamad, et al., "Effect of Recycling on the Rheological and Mechanical Properties of Poly(Lactic Acid)/Polystyrene Polymer Blend," Journal of Material Science, Vol. 46, No. 9, 2011, pp. 3013-3019. doi:10.1007/s10853-010-5179-8
[17] B. G. Girija, et al., "Thermal Degradation and Mechanical Properties of PET Blends," Polymer Degradation and Stability, Vol. 90, No. 1, 2005, pp. 147-153.

[18] H. Chen, et al., "Non-Isothermal Crystallization of PET/ PLA Blends," Thermochimica Acta, Vol. 492, No. 1-2, 2009, pp. 61-66. doi:10.1016/j.tca.2009.04.023

[19] J. B. Lee, et al., "Compatibilizing Effects for Improving Mechanical Properties of Biodegradable Poly(Lactic Acid) and Polycarbonate Blends," Polymer Degradation and Stability, Vol. 96, No. 4, 2011, pp. 553-560. doi:10.1016/j.polymdegradstab.2010.12.019

[20] G. Stoclet, et al., "Morphology, Thermal Behavior and Mechanical Properties of Binary Blends of Compatible Biosourced Polymers: Polylactide/Polyamide11," Polymer, Vol. 52, No. 6, 2011, pp. 1417-1425. doi:10.1016/j.polymer.2011.02.002

[21] Y. Li and H. Shimizu, (2009) "Improvement in Toughness of Poly(L-Lactide) (PLLA) through Reactive Blending with Acrylonitrile-Butadiene-Styrene Copolymer (ABS): Morphology and Properties," European Polymer Journal, Vol. 45, No. 3, 2011, pp. 738-746. doi:10.1016/j.eurpolymj.2008.12.010

[22] L. C. Simoes, et al., "Mechanical Properties of Poly(ECaprolactone) and Poly(Lactic Acid) Blends," Journal of Applied Polymer Science, Vol. 112, No. 1, 2009, pp. 345-352. doi:10.1002/app.29425

[23] Y. Zhang, et al., "Effect of Steady Shear on the Morphology of Biodegradable Poly(E-Caprolactone)/Polylactide Blend," Polymer Engineering \& Science, Vol. 49, No. 12, 2009, pp. 2293-2300. doi:10.1002/pen.21456

[24] D. Wu, et al., "Viscoelastic Interfacial Properties of Compatibilized Poly(E-Caprolactone)/Polylactide Blend," Journal of Polymer Science Part B: Polymer Physics, Vol. 48, No. 7, 2010, pp. 756-765. doi:10.1002/polb.21952

[25] T. Takayama and M. Todo, "Improvement of Impact Fracture Properties of PLA/PCL Polymer Blend Due to LTI Addition," Journal of Materials Science, Vol. 41, No. 15, 2006, pp. 4989-4992. doi:10.1007/s10853-006-0137-1

[26] T. Takayama, et al., "Effect of LTI Content on Impact Fracture Property of PLA/PCL/LTI Polymer Blends," Journal of Materials Science, Vol. 41, No. 15, 2006, pp. 6501-6504. doi:10.1007/s10853-006-0611-9

[27] T. Takayama, et al., "Effect of Annealing on the Mechanical Properties of PLA/PCL and PLA/PCL/LTI Polymer Blends," Journal of the Mechanical Behavior of Biomedical Materials, Vol. 4, No. 3, 2011, pp. 255-260. doi:10.1016/j.jmbbm.2010.10.003

[28] J. W. Park and S. S. Im, "Phase Behavior and Morphology in Blends of Poly(L-Lactic Acid) and Poly(Butylene Succinate)," Journal of Applied Polymer Science, Vol. 86, No. 3, 2002, pp. 647-655. doi:10.1002/app.10923

[29] A. Bhatia, et al., "Compatibility of Biodegradable Poly (Lactic Acid) (PLA) and Poly(Butylenes Succinate) (PBS) Blends for Packaging Application," Korea-Australia Rheology Journal, Vol. 19, 2007, pp. 125-131.

[30] T. Yokohara and M. Yamaguchi, "Structure and Properties for Biomass-Based Polyester Blends of PLA and 
PBS," European Polymer Journal, Vol. 44, No. 3, 2008, pp. 677-685. doi:10.1016/j.eurpolymj.2008.01.008

[31] R. Wang, et al., "Toughening Modification of PLLA/PBS Blends via in Situ Compatibilization," Polymer Engineering \& Science, Vol. 49, No. 1, 2009, pp. 26-33. doi:10.1002/pen.21210

[32] P. Bae, et al., "Plasticizer Effect of Novel PBS Ionomer in PLA/PBS Ionomer Blends," Macromolecular Research, Vol. 18, No. 5, 2010, pp. 463-471. doi:10.1007/s13233-010-0512-2

[33] L. Jiang, et al., "Study of Biodegradable Polylactide/ Poly(Butylene Adipate-Co-Terephthalate) Blends," Biomacromolecules, Vol. 7, No. 1, 2006, pp. 199-207. doi:10.1021/bm050581q

[34] S. Y. Gu, et al., "Melt Rheology of Polylactide/Poly(Butylene Adipate-Co-Terephthalate) Blends," Carbohydrate Polymers, Vol. 74, No. 1, 2008, pp. 79-85. doi:10.1016/i.carbpol.2008.01.017

[35] F. Signori, et al., "Thermal Degradation of Poly(Lactic Acid) (PLA) and Poly(Butylene Adipate-Co-Tere-phthalate) (PBAT) and Their Blends Upon Melt Processing," Polymer Degradation and Stability, Vol. 94, No. 1, 2009, pp. 74-82. doi:10.1016/j.polymdegradstab.2008.10.004

[36] H. Xiao, et al., "Crystallization Behavior of Fully Biodegradable Poly(Lactic Acid)/Poly(Butylene Adipate-CoTerephthalate) Blends," Journal of Applied Polymer Science, Vol. 112, No. 6, 2009, pp. 3754-3763. doi:10.1002/app.29800

[37] H. Yuan, et al., "Preparation, Characterization, and Foaming Behavior of Poly(Lactic Acid)/Poly(Butylene Adipate-Co-Butylene Terephthalate) Blend," Polymer Engineering \& Science, Vol. 49, No. 5, 2009, pp. 1004-1012. doi:10.1002/pen.21287

[38] N. Zhang, et al., "Preparation and Properties of Biodegradable Poly(Lactic Acid)/Poly(Butylene Adipate-Co -Terephthalate) Blend with Glycidyl Methacrylate as Reactive Processing Agent," Journal of Materials Science, Vol. 44, No. 1, 2009, pp. 250-256. doi:10.1007/s10853-008-3049-4

[39] J. T. Yeh, et al., "Compatible and Crystallization Properties of Poly(Lactic Acid)/Poly(Butylene Adipate-Co-
Terephthalate) Blends," Journal of Applied Polymer Science, Vol. 116, 2010, pp. 680-687.

[40] N. Wang, et al., "Preparation and Characterization of Thermoplastic Starch/PLA Blends by One-Step Reactive Extrusion," Polymer International, Vol. 56, No. 11, 2007, pp. 1440-1447. doi:10.1002/pi.2302

[41] N. Wang, et al., "Influence of Citric Acid on the Properties of Glycerol-Plasticized Dry Starch (DTPS) and DTPS/Poly(Lactic Acid) Blends," Starch, Vol. 59, No. 9, 2007, pp. 409-417. doi:10.1002/star.200700617

[42] N. Wang, et al., "Preparation and Characterization of Compatible Thermoplastic Dry Starch/Poly(Lactic Acid)," Polymer Composites, Vol. 29, No. 5, 2008, pp. 551-559. doi:10.1002/pc.20399

[43] N. Wang, et al., "Influence of Formamide and Water on the Properties of Thermoplastic Starch/Poly(Lactic Acid) Blends," Carbohydrate Polymers, Vol. 71, No. 1, 2008, pp. 109-118. doi:10.1016/j.carbpol.2007.05.025

[44] E. Schwach, et al., "Biodegradable Blends Based on Starch and Poly(Lactic Acid): Comparison of Different Strategies and Estimate of Compatibilization," Journal of Polymers and the Environment, Vol. 16, 2008, pp. 286297.

[45] M. A. Huneault and H. Li, (2011) "Effect of Chain Extension on the Properties of PLA/TPS Blends," Journal of Applied Polymer Science, Vol. 119, 2011, pp. 2439-2448.

[46] S. Lee and J. W. Lee, "Characterization and Pro- cessing of Biodegradable Polymer Blends of Poly(Lactic Acid) with Poly(Butylene Succinate Adipate)," Korea-Australia Rheology Journal, Vol. 17, 2005, pp. 71-77.

[47] Y. Wang and J. F. Mano, (2007) "Biodegradable Poly(LLactic Acid)/Poly(Butylene Succinate-Co-Adipate) Blends: Miscibility, Morphology, and Thermal Behavior," Journal of Applied Polymer Science, Vol. 105, No. 6, 2010, pp. 3204-3210. doi:10.1002/app.25049

[48] Z. Tadmor and C. G. Gogos, "Principles of Polymer Processing," John Wiley \& Sons Publishing, New York, 2006.

[49] E. B. Bagley, "End Corrections in the Capillary Flow of Polyethylene," Journal of Applied Physics, Vol. 28, No. 5, 1957, pp. 624-627. doi:10.1063/1.1722814 